Textures and Microstructures, Vol. 34, pp. 197-204 Reprints available directly from the publisher Photocopying permitted by license only
(C) 2000 OPA (Overseas Publishers Association) N.V.

Published by license under the Gordon and Breach Science Publishers imprint. Printed in Malaysia.

\title{
THE GROWTH OF OXIDE SCALES ON TEXTURED NICKEL
}

\author{
F. CZERWINSKI and J.A. SZPUNAR* \\ Department of Metallurgical Engineering McGill University, \\ Montreal, 113A 2B2 Canada
}

(Received 10 January 1999)

\begin{abstract}
Improvement in the understanding of the influence of crystallographic texture on the diffusion behavior of protective oxides, formed at high temperatures on metallic substrates, is being sought through the study of a simple model system such as nickel-nickel oxide. Examples of textures in metallurgical nickel products and the correlation between the substrate and oxide textures, are discussed. Techniques of surface texturing are suggested and the texture leading to the highest oxidation resistance is selected on the basis of existing experimental evidence.
\end{abstract}

Keywords: High temperature oxidation; Electrodeposition; NiO; Thin films

\section{INTRODUCTION}

The oxidation of many transition metals occurs principally by the transport of metal cations to the gasoxide interface and subsequent reaction to form new oxide. At temperatures less than one-half the oxide melting point, the dominant transport mechanism of metal ions is through grain boundaries rather than via point defects within the oxide lattice (Smeltzer, 1989). This suggests the importance of grain boundary density and structure in controlling oxidation resistance.

The primary factor affecting the structure of oxide grain boundaries is the crystallographic texture, which in turn is influenced by the crystallographic orientation (texture) of the metallic substrate (Czerwinski and Szpunar, 1998a). While the bulk texture of metallurgical products

\footnotetext{
* Corresponding author.
} 
depends on manufacturing technology, the surface texture, which mainly controls corrosion properties, can be effectively modified by various surface treatments. Some methods of surface texturing to optimize corrosion behavior were described recently (Czerwinski and Szpunar, 1999).

This paper contains data supporting the importance of crystallographic texture research in improving the high temperature oxidation resistance of metals.

\section{EXPERIMENTAL}

The research materials used in this study were $\mathrm{Ni}$ sheets and rods produced by cold rolling and extrusion, respectively. Two techniques of surface finishing were employed: mechanical polishing with $1 \mu \mathrm{m}$ diamond paste and chemical etching. Moreover, polycrystalline $\mathrm{Ni}$ with various textures were produced by electrodeposition, using Watt's and chloride electrolytes at a temperature of $50^{\circ} \mathrm{C}$ and a $\mathrm{pH}$ value between 0.5 and 5 (Karayannis and Petermarakis, 1995). The process was carried out galvanostatically at a current density between 1 and $10 \mathrm{~A} \mathrm{dm}^{-2}$. Oxides were grown at a temperature of $700-800^{\circ} \mathrm{C}$ in pure oxygen and in air. The textures of the Ni substrates and $\mathrm{NiO}$ films were measured using a D-500 Siemens X-ray goniometer and MoK $\alpha$ radiation. Pole figures were obtained using the reflection technique tip to a maximum tilt of $80^{\circ}$ in $5^{\circ}$ polar and radial intervals. The results were corrected for absorption and defocussing using a standard random specimen prepared from $\mathrm{NiO}$ powder; the intensities on the pole figures are shown as multiples of intensities from a random specimen.

\section{RESULTS}

\section{Substrate Nature and Oxidation Rate}

The importance of surface finishing in the oxidation of polycrystalline $\mathrm{Ni}$ is well documented in our earlier studies (Czerwinski and Smeltzer, 1993). Polycrystalline Ni with the $\langle 111\rangle$ texture and a surface deformed by mechanical polishing, oxidized at a rate of over one order of magnitude higher than the same material with the surface finished by chemical etching. Since chemical etching is known to reveal the atomic 
structure of the grains, the differences observed indicate the importance of the crystallographic orientation of a surface exposed to a corrosive environment. Of the two crystal orientations of (100) and (111), a higher oxidation rate was exhibited by the (100)Ni face. The rate constants for $\mathrm{NiO}$ growth on the (100) face are very similar to that measured for the polycrystalline, mechanically polished $\mathrm{Ni}$ (Czerwinski and Szpunar, 1998a). Thus, the oxidation kinetics measurements show clearly that in order to increase oxidation resistance at high temperatures, the surface texture should be produced with $\{111\}$ planes parallel to the specimen surface.

\section{The Texture of Metallurgical Ni Products}

During metallurgical processing, the hot, cold deformation and annealing follow the casting. As a result, $\mathrm{Ni}$ grains exhibit a preferential arrangement, which depends upon particular manufacturing technology. The simplest products obtained by metallurgical processing are sheets and rods. An example of the texture of cold rolled and annealed $0.8 \mathrm{~mm}$ thick Ni sheet has been presented in Fig. 1(a). The orientation of $\mathrm{Ni}$ grains is described by a $\{100\}\langle u v w\rangle$ texture, which means that the $\{100\}$ planes are parallel to the sheet surface and the $\langle u v w\rangle$ direction is oriented along the rolling direction. The texture of an Ni rod with a diameter of $15 \mathrm{~min}$, produced by cold extrusion and annealing, is represented by two the single fiber components of $\langle 111\rangle$ and $\langle 100\rangle$ with intensities of 2.9 and 3.4 and aligned along the rod axis (Fig. 1(b)). This implies that the rod's outer surface, which is exposed to the

(a)

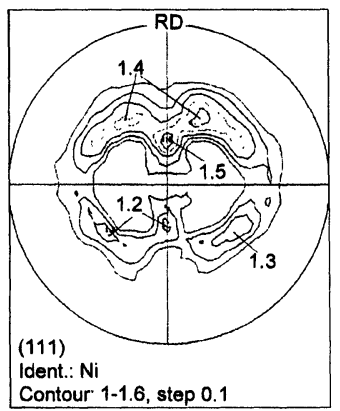

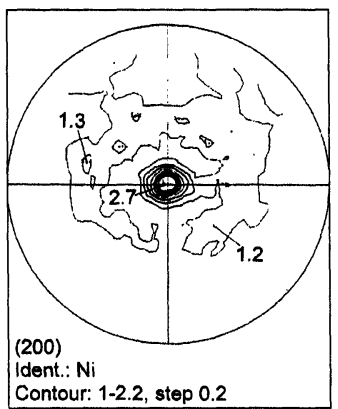

FIGURE 1(a)

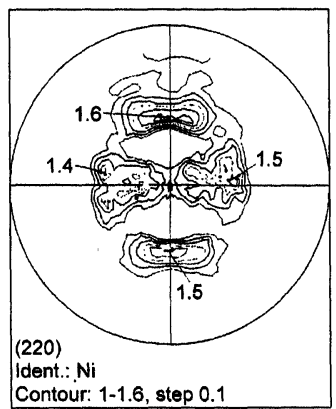

Contour: $1-1.6$, step 0.1 
(b)
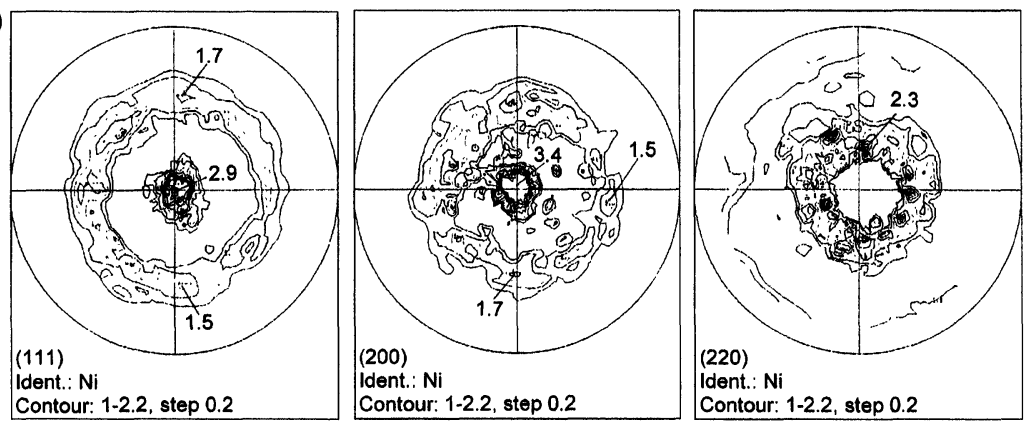

FIGURE 1(b)

FIGURE 1 Pole figures representing typical textures for metallurgically manufactured nickel: (a) an $0.8 \mathrm{~mm}$ thick foil obtained by cold rolling; (b) an $15 \mathrm{~mm}$ diameter rod obtained by cold extrusion. Both materials were annealed in an argon atmosphere at $900^{\circ} \mathrm{C}$ for $1 \mathrm{~h}$.

environment and subjected to corrosion is randomly oriented. The lack of a beneficial $\{111\}$ component indicates that the bulk textures obtained, due to the conventional metallurgical processing of sheets and rods are not compatible with their oxidation resistance and may lead to high oxidation rates. One of several possibilities for improving $\mathrm{Ni}$ oxidation resistance is to modify the texture of the surface layer using electrodeposition technology.

\section{Factors Affecting the Oxide Texture}

The oxide texture depends on the substrate nature and growth parameters (Czerwinski and Szpunar, 1998b). To estimate the relative contribution of each individual factor, the surface of polycrystalline Ni was finished by two techniques for the experiment. Mechanical polishing was applied to introduce the physical damage and to promote the nucleation of the randomly oriented oxide and chemical polishing was used to reveal the atomic structure of the surface and to promote epitaxial growth. The NiO formed after chemical polishing is highly nonuniform and the oxide thickness and morphology strongly depend on the orientation of $\mathrm{Ni}$ grains and on the type of $\mathrm{Ni}$ grain boundary (Fig. 2(a)). In contrast, the $\mathrm{NiO}$ formed on a mechanically polished substrate is uniform in thickness and does not reveal the influence of substrate crystallography (Fig. 2(b)). 

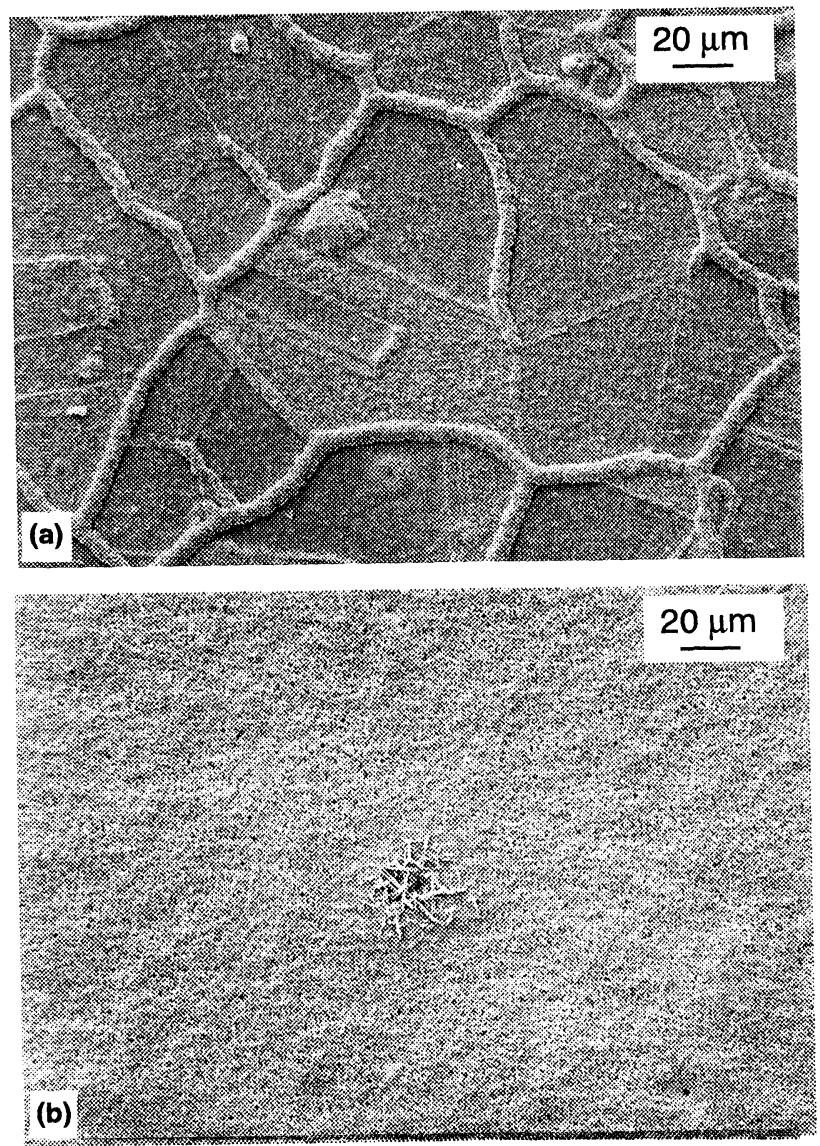

FIGURE 2 The influence of nickel surface finishing on the morphology of NiO: (a) $\mathrm{NiO}$ formed on a chemically polished surface; (b) $\mathrm{NiO}$ formed on a mechanically polished surface. Oxidation in oxygen at $700^{\circ} \mathrm{C}$ for $70 \mathrm{~h}$.

The pole figures of the $\mathrm{Ni}$ substrate and $\mathrm{NiO}$ films formed after both techniques of surface finishing also show the crucial role of the substrate texture. Exposure to oxygen causes individual $\mathrm{Ni}$ grains to oxidize at different rates. The NiO texture $\{100\}\langle u v w\rangle$ formed as a result of the exposure of the Ni substrate for $15 \mathrm{~h}$ at $1073 \mathrm{~K}$ (Fig. 3(a)), supports the influence of epitaxy between the oxide and substrate.

Conversely, pole figures of $\mathrm{NiO}$ formed on a mechanically polished $\mathrm{Ni}$ do not show the influence of the substrate (Fig. 3(b)). Instead, 
(a)
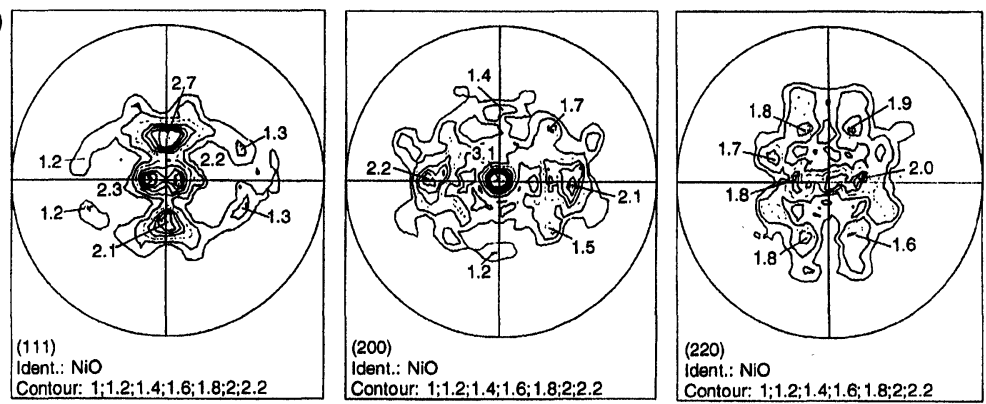

(b)
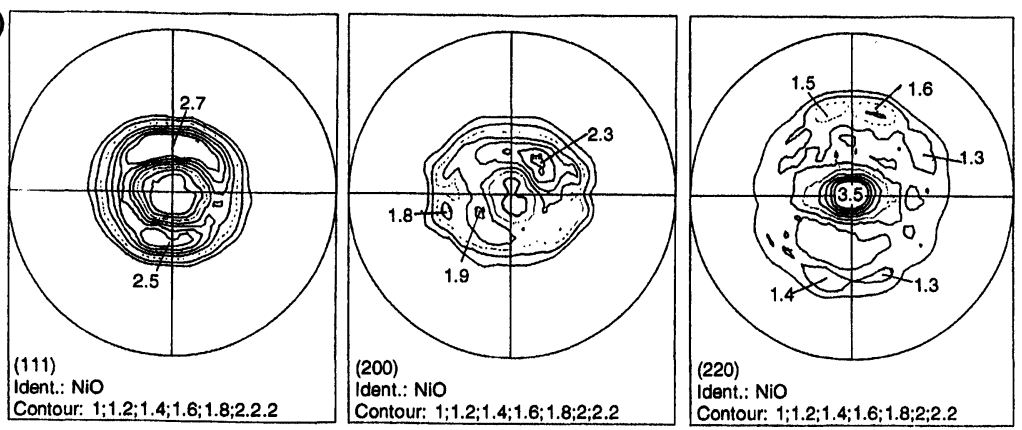

FIGURE 3 Pole figures representing textures of $\mathrm{NiO}$ formed nickel foil finished by chemical polishing (a) and mechanical polishing (b). Oxidation in I atm of oxygen at $800^{\circ} \mathrm{C}$ for $15 \mathrm{~h}$.

a weak $\{110\}$ fiber texture is developed. Since the initial $\mathrm{NiO}$ formed on mechanically polished $\mathrm{Ni}$ surface is characterized by the random distribution of grain orientations (Czerwinski et al., 1995), the $\langle 110\rangle$ is the growth texture of $\mathrm{NiO}$ in these experimental conditions. The formation of a similar growth texture in $\mathrm{NiO}$ was also observed by Chadwick and Taylor (1985).

\section{Controlling the Surface Texture for Corrosion Resistance Purposes}

$\mathrm{Ni}$ electrodeposits are known for giving numerous, well-defined preferred orientations; including $\langle 100\rangle,\langle 110\rangle,\langle 311\rangle$ and $\langle 211\rangle$. The comparison of literature data (Karayannis and Petermarakis, 1995) and our experimental results show that a strong $\langle 111\rangle$ single-component texture, which is beneficial for oxidation performance, cannot easily be obtained 
in an as-deposited state. Moreover, electrodeposits in general are not in a state of equilibrium and direct oxidation leads to the growth of a randomly oriented oxide. An example is shown in Fig. 4 where Ni with a strong $\langle 100\rangle$ texture (Fig. 4(a)) gives random $\mathrm{NiO}$ with traces of $\langle 110\rangle$

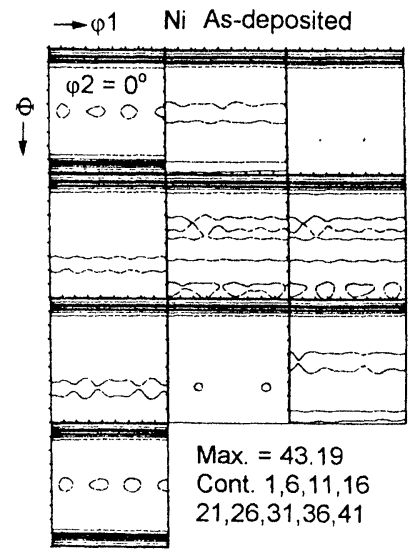

(a) Annealing
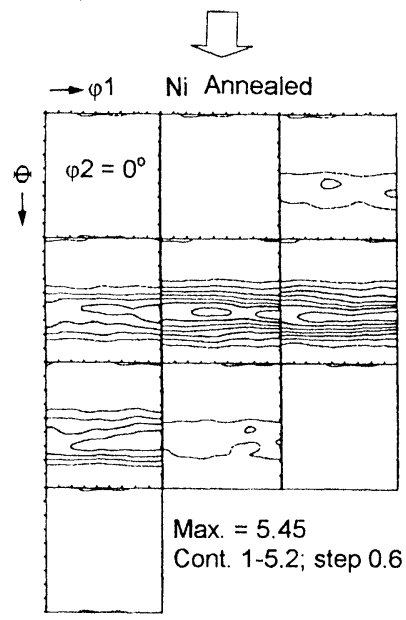

(c)

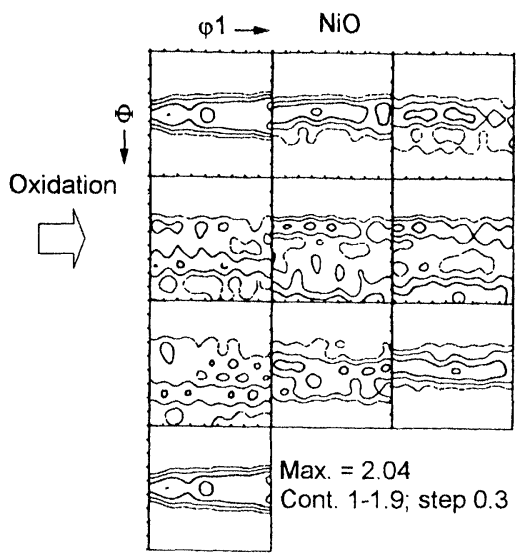

(b)

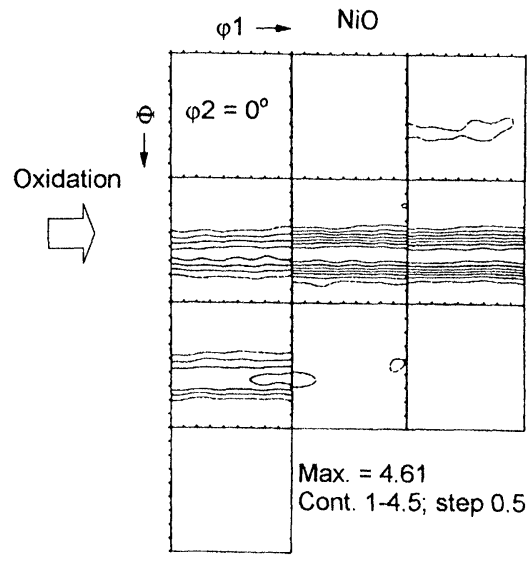

(d)

FIGURE 4 Orientation distribution functions representing textures for electrolytic nickel: (a) as-deposited $\mathrm{Ni}$ with a strong $\langle 100\rangle$ fiber texture; (b) $\mathrm{NiO}$ grown at $800^{\circ} \mathrm{C}$ on as-deposited $\mathrm{Ni}$, random texture with traces of a $\langle 110\rangle$ fiber; (c) $\mathrm{Ni}$ annealed in argon at $800^{\circ} \mathrm{C},\langle 111\rangle$ fiber texture; (d) $\mathrm{NiO}$ grown at $800^{\circ} \mathrm{C}$ on annealed $\mathrm{Ni},\langle 111\rangle$ fiber texture. 
(Fig. 4(b)). In order to be effective in oxidation prevention the electrodeposited layer of $\mathrm{Ni}$ should have a $\langle 111\rangle$ texture and exert an influence on the texture of the growing oxide by promoting epitaxy. The NiO texture expected for a particular case of the (100) and (111) crystal faces of $\mathrm{Ni}$, is discussed in detail elsewhere (Czerwinski and Szpunar, 1998a).

As a result of recrystallization during annealing, a $\langle 111\rangle$ texture develops (Fig. 4(c)). The strengthening of the $\langle 111\rangle$ texture at the expense of a $\langle 100\rangle$ texture, was also observed during the recrystallization of Ni-base alloys (Czerwinski et al., 1997). The presence of a $\langle 111\rangle$ texture in an annealed, i.e. free of structural defects, Ni substrate, is highly beneficial for oxidation resistance because it leads to the growth of epitaxially oriented $\mathrm{NiO}$ films. Indeed a comparison of the ODF of an annealed substrate (Fig. 4(c)) and corresponding oxide (Fig. 4(d)) supports the existence of epitaxy.

\section{CONCLUSIONS}

The crystallographic texture of a metallic substrate plays an important role in oxidation (corrosion) resistance at high temperatures. The texture of typical metallurgical products is not beneficial in terms of their oxidation protection. The modification of substrate texture might be an effective way to improve oxidation resistance. In particular, a two-stage surface treatment composed of the electrodeposition of $\mathrm{Ni}$ with a high $\langle 100\rangle$ texture followed by annealing, produces a surface with a strong $\langle 111\rangle$ texture. As demonstrated elsewhere, this texture of Ni leads to the formation of highly protective and slow growing $\mathrm{NiO}$ scales.

\section{References}

Chadwick, A.T. and Taylor, R.I. (1985) J. Microsopy, 140, 221-242.

Czerwinski, F. and Smeltzer, W.W. (1993) J. Electroch. Soc., 140, 2606-2615.

Czerwinski, F., Szpunar, J.A., Macaulay-Newcombe, R.G. and Smeltzer, W.W. (1995) Oxid. Met., 43, 25-57.

Czerwinski, F., Li, H., Megret, F., Szpunar, J.A., Clark, D.G. and Erb, U. (1997) Scripta Mater., 37, 1967-1972.

Czerwinski, F. and Szpunar, J.A. (1998a) Acta Mater., 46, 1403-1417.

Czerwinski, F. and Szpunar, J.A. (1998b) J. Mater. Sci., 33, 5463-5472.

Czerwinski, F. and Szpunar, J.A. (1999) Corros. Sci., 41, 729-740.

Karayannis, H.S. and Petermarakis, G. (1995) Electroch. Acta, 40, 1079-1092.

Smeltzer, W.W. (1989) Mater. Sci. Forum, 29, 151-172. 